\title{
Structure-Solubility Relationship of CO Dispersion in Model Hydrocarbon Liquids and Heavy Oil Fractions
}

\author{
He Liu,* Shiguang Fan, Jian Wang, Hao Liu, Aijun Guo, Kun Chen, Zongxian Wang, and Litao Wang
}

Cite This: ACS Omega 2021, 6, 23317-23328

Read Online

ABSTRACT: The solubility of CO in heavy oils is an important parameter for designing and optimizing the partial upgrading process of heavy oil under $\mathrm{CO} /$ syngas and water. To study the structure-solubility relationship of $\mathrm{CO}$ dispersion in organic liquids, the solubility of $\mathrm{CO}$ in hydrocarbons ( $n$-hexane, $n$-octane, $n$-hexadecane, cyclohexane, toluene, and 1-methylnaphthalene), petroleum distillates, and residues from Canadian oil sand bitumen was measured at different temperatures and pressures. The dispersion behavior of $\mathrm{CO}$ in different molecules was simulated by the molecular dynamics calculation. The role of water on $\mathrm{CO}$ dispersion in these systems was also explored. Experimental data show that the increase of both paraffinic chain length and aro-

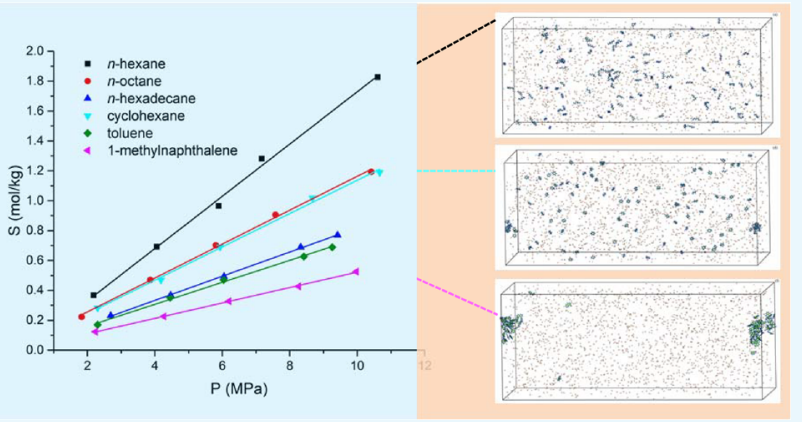
maticity of molecules could hinder the dissolution of CO. By theoretical calculation, it is found that $n$-hexadecane and 1-methylnaphthalene present the strongest self-aggregation tendency, resulting in the low interaction with CO. The intermolecular forces of hydrocarbons appear to be the key factor determining the $\mathrm{CO}$ solubility. The dissolved $\mathrm{H}_{2} \mathrm{O}$ molecules could weaken the intermolecular forces of hydrocarbons and thus increase the CO solubility. Based on the model system study, the solubility of CO in complex petroleum distillates and heavy residues is rationalized by their molecular composition, which is mainly dependent on the relative proportion of paraffins to aromatics.

\section{INTRODUCTION}

The extremely high viscosity and low mobility of heavy oil make it unable to be transported by pipeline or shipment and pose great challenges to the refining process. ${ }^{1}$ As the petroleum supply is becoming heavier and inferior, reducing the viscosity of heavy oil has been a hot spot in both upstream and downstream petroleum industry. Partial upgrading has achieved great attention due to its low capital and operation cost, as well as potentiality to reduce the amount of diluents during the dilution process and avoid high-cost full upgrading. ${ }^{2}$ When the exploited heavy oil is presented as emulsions through hot water extraction or steam injection, further demulsification and water/oil separation are needed prior to partial upgrading. ${ }^{3} \mathrm{Ng}$ and her research group have proposed a single-stage process coupling the emulsion separation and partial upgrading by capturing the highly active in situ hydrogen produced from the water-gas shift reaction (WGSR). ${ }^{4-6}$ This novel process is of great interest for a more efficient and economical partial upgrading of heavy oil.

Typically, heavy oil upgrading with $\mathrm{CO}$ and water involves the liquid oil phase, liquid water phase, gas phase, and solid catalyst phase. This could lead to high interphase mass transfer resistance. ${ }^{7}$ As illustrated in Figure 1, it can be expected that the WGSR occurring in the heavy oil phase would benefit the efficient transferring of in situ hydrogen to heavy oil molecules to some extent. Generally, the molar amount of $\mathrm{CO}$ is far lower than that of water, indicating that $\mathrm{CO}$ acts as the reactant controlling the rate of WGSR. Therefore, knowledge of the solubility of $\mathrm{CO}$ in heavy oil and its fractions is crucial for analyzing the efficiency of in situ hydrogen usage. Additionally, the solubility data are particularly important for understanding the phase equilibrium, establishing the kinetic model of WGSR and hydrogenation, as well as designing and optimizing the upgrading process. $^{8}$

The solubility information of $\mathrm{CO}$ in model hydrocarbons is available in the field of Fischer-Tropsch synthesis. ${ }^{9}$ Srivatsan et al. ${ }^{10}$ and Gao et al. ${ }^{11}$ have measured the solubility of $\mathrm{CO}$ in heavy normal paraffins. Park et al. ${ }^{12}$ and Jáuregui-Haza et al. ${ }^{13}$ reported the solubility data of $\mathrm{CO}$ in aromatic hydrocarbons. For $\mathrm{CO}$ in cyclohexane, the solubility could be found in the study by Gao et al. ${ }^{14}$ The CO solubility experimental measurement in complex heavy oils and heavy fractions is scarcely reported compared with that in model compounds and light fractions. This could be challenging due to their high viscosity and thermal instability at elevated temperatures and pressures as

Received: June 10, 2021

Accepted: August 9, 2021

Published: September 1, 2021 


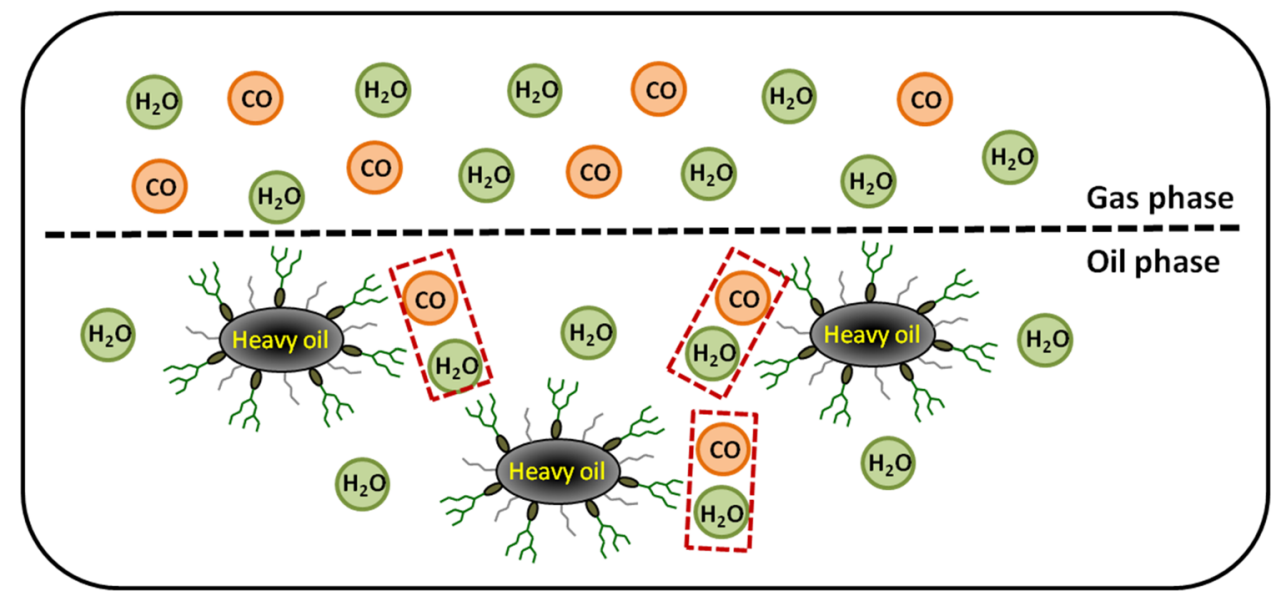

Figure 1. Phase analysis in heavy oil upgrading with $\mathrm{CO}$ and water.

Table 1. Specifications of the Chemicals Used in This Work

\begin{tabular}{lcccc}
\multicolumn{1}{c}{ chemical name } & molecular formula & CAS no. & purity provided by the supplier (mass fraction) \\
$n$-hexane & $\mathrm{C}_{6} \mathrm{H}_{14}$ & $110-54-3$ & $99.7 \%$ & Xilong Chemical Co., Ltd., China \\
$n$-octane & $\mathrm{C}_{8} \mathrm{H}_{18}$ & $111-65-9$ & $99.7 \%$ & Xilong Chemical Co., Ltd., China \\
$n$-hexadecane & $\mathrm{C}_{16} \mathrm{H}_{34}$ & $544-76-3$ & $99.7 \%$ & Xilong Chemical Co., Ltd., China \\
cyclohexane & $\mathrm{C}_{6} \mathrm{H}_{12}$ & $110-82-7$ & $99.7 \%$ & Xilong Chemical Co., Ltd., China \\
toluene & $\mathrm{C}_{7} \mathrm{H}_{8}$ & $108-88-3$ & $99.7 \%$ & Xilong Chemical Co., Ltd., China \\
1-methylnaphthalene & $\mathrm{C}_{11} \mathrm{H}_{10}$ & $90-12-0$ & $99.7 \%$ & Xilong Chemical Co., Ltd., China \\
carbon monoxide & $\mathrm{CO}$ & $630-08-0$ & $99.99 \%$ & Tianyuan Gas Manufacturing Co., Ltd., China
\end{tabular}

well as a lack of an accurate and simple determination method. ${ }^{15}$ It is the same case for hydrogen solubility measurement in heavy oil. ${ }^{16-19}$ Wang and his group have developed a modified direct method to measure hydrogen solubility and have successfully applied it in heavy residues, which provided an efficient method to measure CO solubility in heavy oils. ${ }^{20}$ Most of the previous researches mainly aimed at the experimental measurement and predictive model development for solubility estimation. ${ }^{9-14,21,22}$ There is still a lack of systematic study to deal with the influence of intrinsic structures on the $\mathrm{CO}$ dissolving behavior at the molecular level. In recent years, molecular dynamics simulation has been an important technique to explore the microdiffusion behavior of gases in liquids. ${ }^{23-26}$ By combining the experimental study and molecular dynamics simulation, the effect of underlying fundamental interactions on the macroscopic dispersion property of $\mathrm{CO}$ in different molecules can be explored. On these bases, the solubility of $\mathrm{CO}$ in different complex heavy oils could be better understood.

In this work, the solubility of $\mathrm{CO}$ in different alkanes, cycloalkanes, and aromatics at different temperatures and pressures is measured by the modified method previously reported. ${ }^{20}$ The influence of molecular structures on $\mathrm{CO}$ solubility is explained by the molecular dynamics simulation. Finally, the CO solubility in different heavy oil distillates and residues is then examined and discussed in terms of the molecular structures. The effect of water on the $\mathrm{CO}$ solubility in hydrocarbons and complex heavy oil fractions is also explored.

\section{EXPERIMENTAL SECTION}

2.1. Materials. The description of the chemicals, including chemical names, molecular formula, CAS registry number, purity, and chemical source of the supplier, is summarized in Table 1. Different distillates and heavy residues were separated from Canadian oil sand bitumen (a typical heavy oil, HO) by true boiling point distillation, including gasoline $(\mathrm{bp}<453 \mathrm{~K}$, FA), diesel (bp 453-623 K, FB), vacuum gas oil (bp 623-693 $\mathrm{K}, \mathrm{FC}$ ), atmospheric residue (bp > $623 \mathrm{~K}, \mathrm{AR}$ ), and vacuum residue ( $b p>693 \mathrm{~K}, \mathrm{VR}$ ). Main properties of these heavy oil fractions were listed in Table 2 . The density was measured with a pycnometer at $293 \mathrm{~K}$. The viscosity was measured using a capillary tube viscometer at 323 and $393 \mathrm{~K}$. Determination of the average molecular weight was conducted on a Knauer K-7000 vapor-pressure osmometer. Elemental composition was determined using a Vario EL III elemental analyzer from Elementar Company. The SARA analysis was performed by the method described in previous literature. ${ }^{27}$ The hydrocarbon analysis of FA was finished by a CP-3800 GC equipment, while that of FB and FC was obtained using an Agilent 7890B-5977 GC equipment.

2.2. Measurement of CO Solubility in Feedstocks. The solubility of $\mathrm{CO}$ was measured in the modified apparatus previously reported by Ji et al., ${ }^{20}$ which is briefly described here. About $80 \mathrm{~g}$ of degassed feed liquid was loaded into a $300 \mathrm{~mL}$ autoclave. After purging with $\mathrm{CO}$ three times to remove air as much as possible, the autoclave was heated to the given temperature and charged with a certain pressure of $\mathrm{CO}$. Then, stirring was carried out and the pressure started to drop due to the diffusion of $\mathrm{CO}$ into the liquids. Due to the high viscosity of heavy residue, when measuring the CO solubility, the mixture of heavy residue and water was stirred for an adequate time (about $1 \mathrm{~h}$ ) at the given temperature. The pressure in the autoclave was monitored in real time using the pressure gauge with a precision of $\pm 0.001 \mathrm{MPa}$. When the pressure became unchanged, the stirring was stopped and the autoclave was allowed to stand still for an adequate time to ensure that the bubbles escaped completely. In this case, the equilibrium was established. Subsequently, about $2 \mathrm{~g}$ of the sample was taken into the sampling flask. The dissolved $\mathrm{CO}$ would escape out and pressurize the 
Table 2. Main Properties of the Feed Heavy Oil Fractions

\begin{tabular}{|c|c|c|c|c|c|c|}
\hline sample & $\mathrm{FA}^{a}$ & $\mathrm{FB}^{b}$ & $\mathrm{FC}^{c}$ & $\mathrm{HO}^{d}$ & $\mathrm{AR}^{e}$ & $\mathrm{VR}^{f}$ \\
\hline density at $293 \mathrm{~K}, \mathrm{~g} / \mathrm{cm}^{3}$ & 0.7118 & 0.8916 & 0.9566 & 1.008 & 1.009 & 1.013 \\
\hline viscosity at $323 \mathrm{~K}, \mathrm{~mm}^{2} / \mathrm{s}$ & 1.68 & 5.19 & 41.8 & & & \\
\hline viscosity at $393 \mathrm{~K}, \mathrm{~mm}^{2} / \mathrm{s}$ & & & & 122 & 523 & 5322 \\
\hline molecular weight, g/mol & 232 & 283 & 319 & 520 & 782 & 1403 \\
\hline \multicolumn{7}{|c|}{ Elemental analysis } \\
\hline C, wt \% & 85.68 & 85.74 & 85.81 & 84.02 & 83.66 & 84.87 \\
\hline $\mathrm{H}$, wt $\%$ & 12.78 & 12.65 & 11.66 & 10.42 & 10.39 & 10.18 \\
\hline S, wt $\%$ & 1.24 & 1.48 & 2.32 & 4.86 & 5.12 & 4.02 \\
\hline $\mathrm{N}$, wt \% & 0.06 & 0.09 & 0.10 & 0.38 & 0.63 & 0.81 \\
\hline $\mathrm{O}$, wt $\%^{g}$ & 0.24 & 0.04 & 0.11 & 0.32 & 0.20 & 0.12 \\
\hline $\mathrm{H} / \mathrm{C}$ atomic ratio & 1.79 & 1.77 & 1.63 & 1.51 & 1.49 & 1.44 \\
\hline \multicolumn{7}{|c|}{ SARA composition } \\
\hline saturates, wt \% & & & 64.86 & 35.12 & 25.26 & 19.35 \\
\hline aromatics, wt $\%$ & & & 34.70 & 40.81 & 40.23 & 38.99 \\
\hline resins, wt \% & & & 0.44 & 21.51 & 25.82 & 29.67 \\
\hline asphaltenes, wt \% & & & 0 & 2.56 & 8.69 & 11.99 \\
\hline
\end{tabular}

${ }^{a}$ Gasoline (bp < $\left.453 \mathrm{~K}\right) .{ }^{b}$ Diesel (bp 453-623 K). ${ }^{c}$ Vacuum gas oil (bp 623-693 K). ${ }^{d}$ Typical heavy oil (Canadian oil sand bitumen). ${ }^{e}$ Atmospheric residue $(\mathrm{bp}>623 \mathrm{~K}) .{ }^{f}$ Vacuum residue $(\mathrm{bp}>693 \mathrm{~K}) .{ }^{g}$ The oxygen content is obtained by the subtraction method.
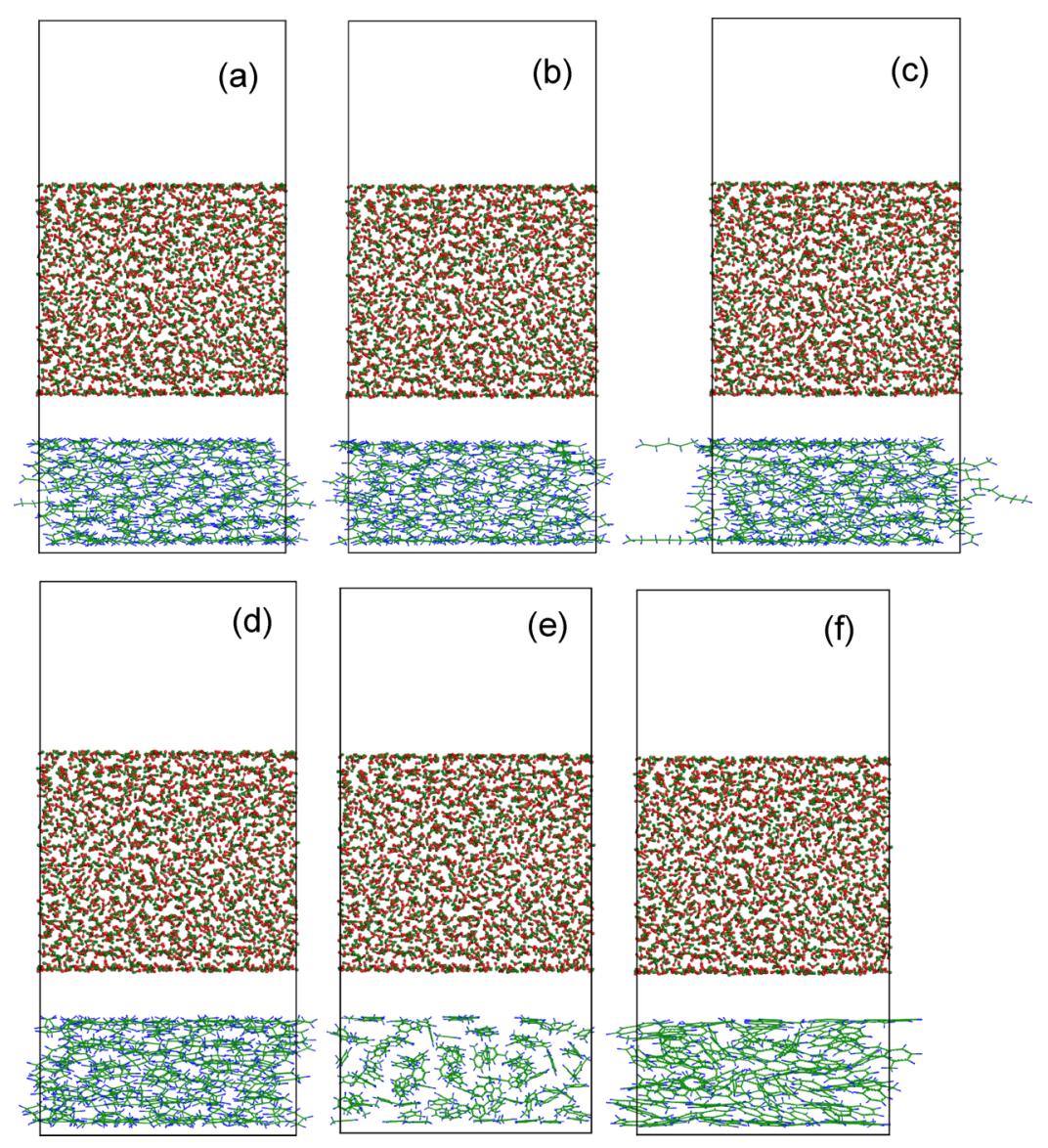

Figure 2. Simulation snapshots of CO-hydrocarbon systems. (a) $107 n$-hexane, (b) 65 n-octane, (c) 41 -hexadecane, (d) 110 cyclohexane, (e) 100 toluene, and (f) 65 1-methylnaphthalene.

distillated water from the surge flask into the volumetric cylinder. When the sampling flask was cooled to room temperature, the volume change of the water in the volumetric cylinder was obtained by adjusting the liquid levels in the measure system. The volume of CO dissolved in the sample could be calculated after deducting the volume of the liquid sample. Taking $\mathrm{CO}$ as an ideal gas, the solubility of $\mathrm{CO}$ can be obtained based on the state equation. The vapor pressure of feed liquids was simultaneously measured to estimate the partial pressure of $\mathrm{CO}$ during the procedure, referenced from Ji et al. ${ }^{20}$

The measurement accuracy of $\mathrm{CO}$ solubility in model compounds was evaluated by comparing the result in ethanol with the available data reported by previous researchers. ${ }^{21}$ Results were shown as supporting information in Figure S1. It can be seen that the solubility of $\mathrm{CO}$ in ethanol by the modified method agrees well with the data in the literature with a 

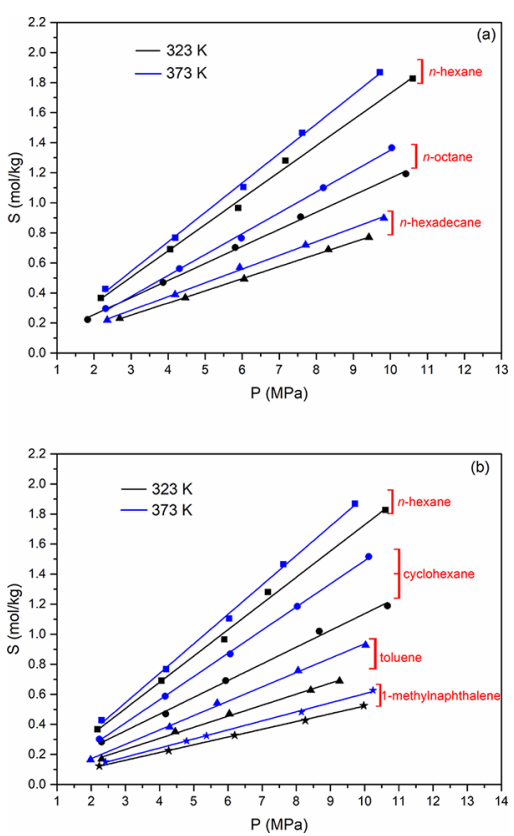

Figure 3. Solubility of $\mathrm{CO}$ versus pressure in model hydrocarbons at 323 and $373 \mathrm{~K}$. (a) $n$-hexane, $n$-octane, and $n$-hexadecane and (b) $n$ hexane, cyclohexane, toluene, and 1-methylnaphthalene.

deviation within $\pm 5 \%$. The CO solubility in selected model hydrocarbons was measured at least three times, and the error is limited to within $\pm 5 \%$. The standard deviation in complicated heavy oil fractions has been presented along with the data.

2.3. Molecular Simulation Method. In this work, molecular dynamics simulations were performed using the Material Studio 7.0 simulation package. First, the molecules of $\mathrm{CO}$ and hydrocarbons were constructed and then the Forcite geometry optimization was carried out. The Smart algorithm was set for the preliminary optimization step. Second, the molecular boxes of $2000 \mathrm{CO}$ and certain numbers of different hydrocarbons with the same mass were created by the amorphous cell. The size of the boxes was dependent on the number of molecules. Then, the simulation box of CO molecules and that of hydrocarbon molecules were placed in the same simulated space with a thickness of $20 \AA$, and a certain vacuum lamella with a thickness of $5 \AA$ was set between them, as shown in Figure 2. These systems were subsequently subjected to energy minimization by Forcite geometry optimization to get a stable structure. The algorithm was set to be the steepest descent method. The optimized systems were equilibrated in NVT simulation and NPT simulation successively. The NHL thermostat and Berendsen barostat were applied to control the temperature of NVT simulation and the pressure of NPT simulation with random initial velocities and a time step of $1.0 \mathrm{fs}$. The total time of NVT simulation and that of NPT simulation were 100 and $300 \mathrm{ps}$, respectively. The force field was selected as COMPASS, and the summation method was set to be the Ewald model. The variations of energies and temperature versus time during NVT and NPT simulation for the systems in the present work indicate that the energies during NVT simulation vary within $\pm 100 \mathrm{kcal} / \mathrm{mol}$ while the temperature during NPT simulation varies within $\pm 10 \mathrm{~K}$, which means that the simulations have been equilibrated. The typical result for the $2000 \mathrm{CO}+107$ $n$-hexane system versus time is shown in Figure S2 as supporting information.

\section{RESULTS AND DISCUSSION}

3.1. CO Dissolution in Different Hydrocarbons. Figure 3 shows the solubility of $\mathrm{CO}(S)$ dissolved in model hydrocarbons with the change of pressure $(P)$ at 323 and $373 \mathrm{~K}$. It is obvious that the solubility of $\mathrm{CO}$ in alkanes, cycloalkanes, and aromatics increases linearly with the pressure increasing. The high temperature also facilitates the dissolution of CO. The rise of solubility with pressure is faster at a relatively higher temperature. The dissolution of $\mathrm{CO}$ implies the intermolecular interaction of $\mathrm{CO}$ with hydrocarbons. Since the $\mathrm{CO}$ molecule has a low dipole moment of 0.10 , the main van der Waals force
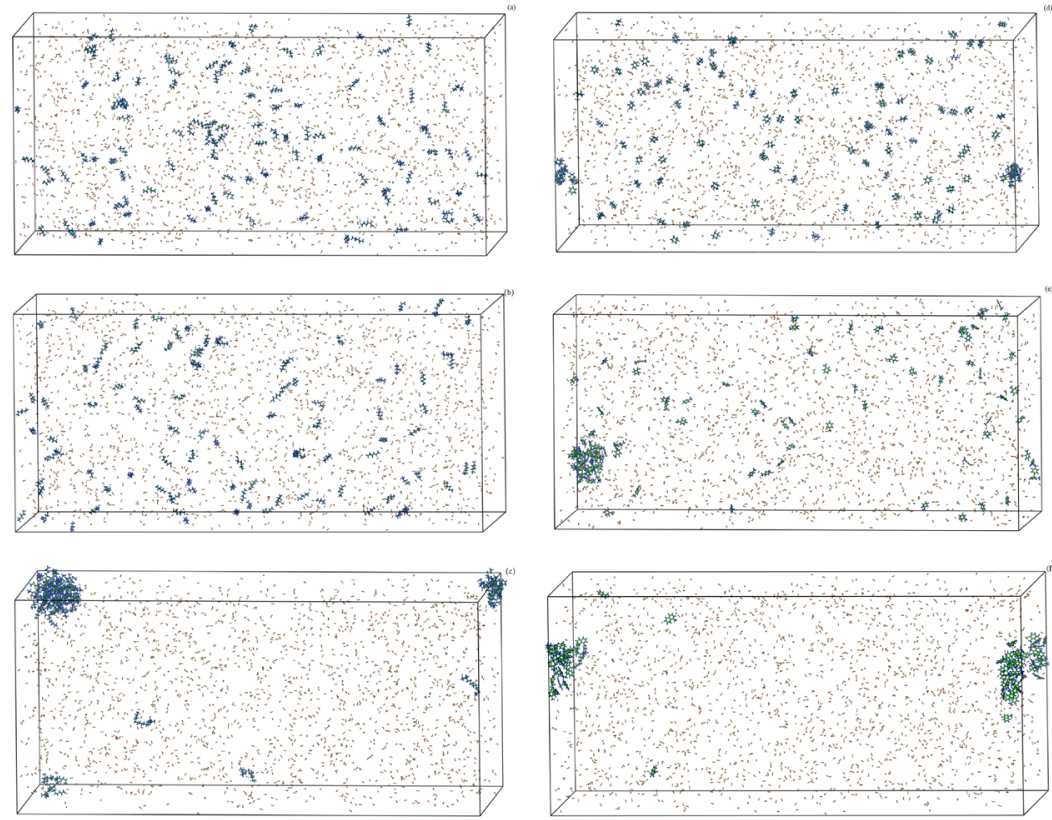

Figure 4. The simulated configurations of $2000 \mathrm{CO}$ molecules and certain numbers of hydrocarbons. (a) $107 n$-hexane, (b) 65 n-octane, (c) $41 n$ hexadecane, (d) 110 cyclohexane, (e) 100 toluene, and (f) 65 1-methylnaphthalene. 

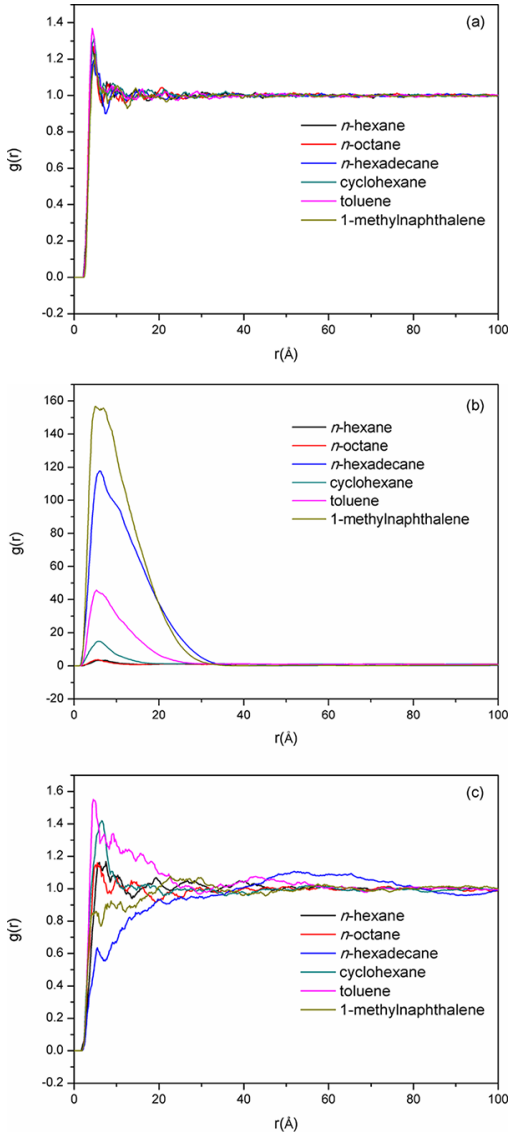

Figure 5. RDF of different molecules at $300 \mathrm{~K}$ and $1 \mathrm{MPa}$. (a) CO-CO molecules, (b) hydrocarbon-hydrocarbon molecules, and (c) COhydrocarbon molecules.

within hydrocarbon molecules, $\mathrm{CO}$ molecules, and between hydrocarbon and $\mathrm{CO}$ molecules is the London force. High pressure could decrease the distance between hydrocarbon and $\mathrm{CO}$ molecules, resulting in stronger London force, as stated by Yang et al. ${ }^{28-31}$ When more $\mathrm{CO}$ molecules are pushed into the hydrocarbons, the distance within hydrocarbon molecules can be increased and weaker London force can be expected, which benefits $\mathrm{CO}$ molecules to get into the liquid phase. Consequently, a higher solubility is observed at a higher pressure. As temperature increases, the increased distance between $\mathrm{CO}$ and hydrocarbon molecules could block the diffusion of $\mathrm{CO}$, while the increased distance within hydrocarbon molecules could favor the intramolecular interaction of $\mathrm{CO}$. Unlike $\mathrm{CO}_{2}$ dissolution in organic liquids, ${ }^{28-31}$ the positive role of temperature appears to exceed the negative one for $\mathrm{CO}$ dissolution.

Under the same conditions, the solubility of CO in $n$-alkanes decreases with the length of carbon chain increases. This suggests that the long paraffinic side chain hinders the intramolecular interactions with $\mathrm{CO}$. The solubility of $\mathrm{CO}$ decreases in the order of $n$-hexane $>$ cyclohexane $>$ toluene $>1$-methylnaphthalene. It indicates that the solubility of $\mathrm{CO}$ in aromatics tends to be lower than that in naphthenic and paraffinic hydrocarbons. Furthermore, a rise of the aromaticity of hydrocarbons restrains the dissolution of $\mathrm{CO}$. The effect of pressure on the solubility of $\mathrm{CO}$ in $n$-alkanes with a smaller carbon number is much stronger.

To further reveal the relationship between the inherent molecular structures of hydrocarbons and the CO solubility, the dispersion property of $\mathrm{CO}$ in hydrocarbons was tentatively studied through a molecular dynamics simulation approach.
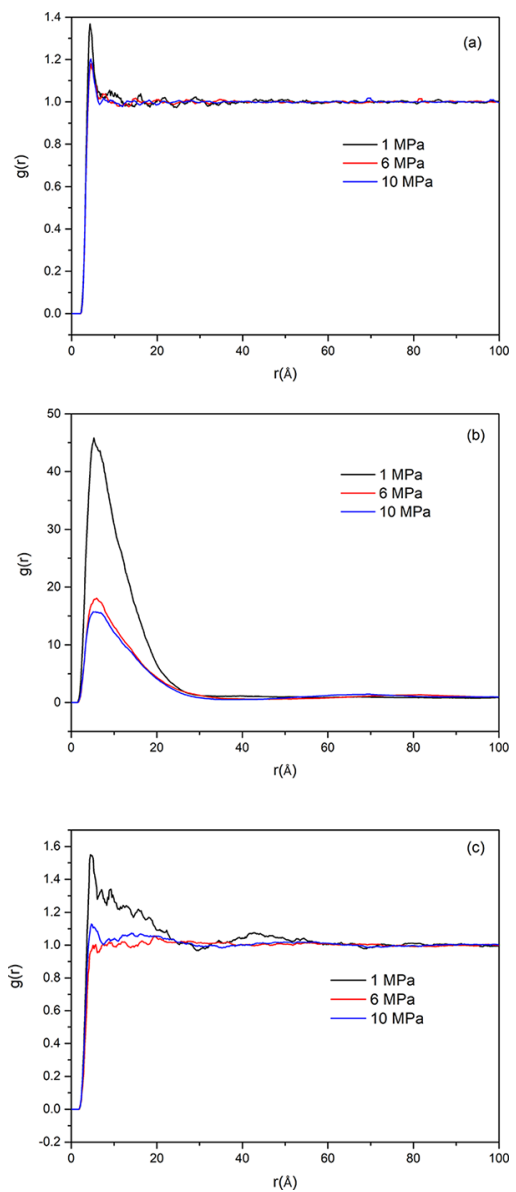

Figure 6. $\mathrm{RDF}$ of molecules in toluene $+\mathrm{CO}$ at $300 \mathrm{~K}$ under different pressures. (a) $\mathrm{CO}-\mathrm{CO}$ molecules, (b) toluene-toluene molecules, and (c) $\mathrm{CO}$-toluene molecules.

Figure 4 displays the simulated configurations of $2000 \mathrm{CO}$ molecules and certain numbers of hydrocarbons with the same mass. Results show that $\mathrm{CO}$ molecules diffuse sufficiently in $n$-hexane and $n$-octane. Meanwhile, $n$-hexadecane exhibits aggregated structures in the $\mathrm{CO}+n$-hexadecane system obviously. This could be rationalized by the stronger London forces of linear alkane molecules with longer alkyl chains. ${ }^{29}$ In contrast, cyclohexane molecule with the shape of a chair or boat and aromatic molecules with a ring show a larger surface area of contact than the linear alkane molecules. Meanwhile, the polarizability of cyclohexane and aromatics is stronger. Therefore, the London forces within cyclohexane and aromatics are stronger. $^{28}$ This is the reason why an obvious aggregation behavior can also be observed for the aromatics and tends to be more distinct as the aromaticity becomes much higher. It clearly indicates that the diffusion of $\mathrm{CO}$ is restricted by the hydrocarbon molecules with longer alkyl side chains and higher aromatic moieties, which is well supported by the above solubility measurements.

Figure 5 shows the radial distribution function (RDF) of $\mathrm{CO}-\mathrm{CO}$ molecules, hydrocarbon-hydrocarbon molecules, and $\mathrm{CO}-$ hydrocarbon molecules at $300 \mathrm{~K}$ and $1 \mathrm{MPa}$. A peak of $\mathrm{RDF}$ of $\mathrm{CO}-\mathrm{CO}$ molecules lower than 1.3 is found at a radius $(r)$ of about $0.50 \mathrm{~nm}$ that is slightly higher than the diameters of $\mathrm{CO}$ molecules. This suggests the $\mathrm{CO}$ molecules are shown as aggregates with a very low aggregation degree in $\mathrm{CO}+$ hydrocarbons systems. The RDF of hydrocarbon-hydrocarbon 

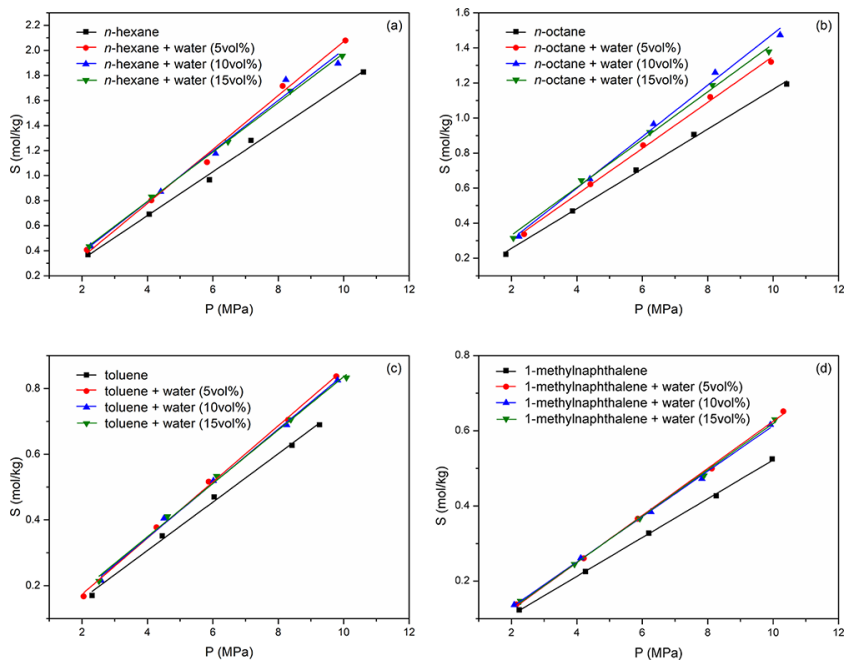

Figure 7. Solubility of $\mathrm{CO}$ versus pressure in model compounds with different amounts of water at $323 \mathrm{~K}$. (a) $n$-hexane, (b) n-octane, (c) toluene, and (d) 1-methylnaphthalene.
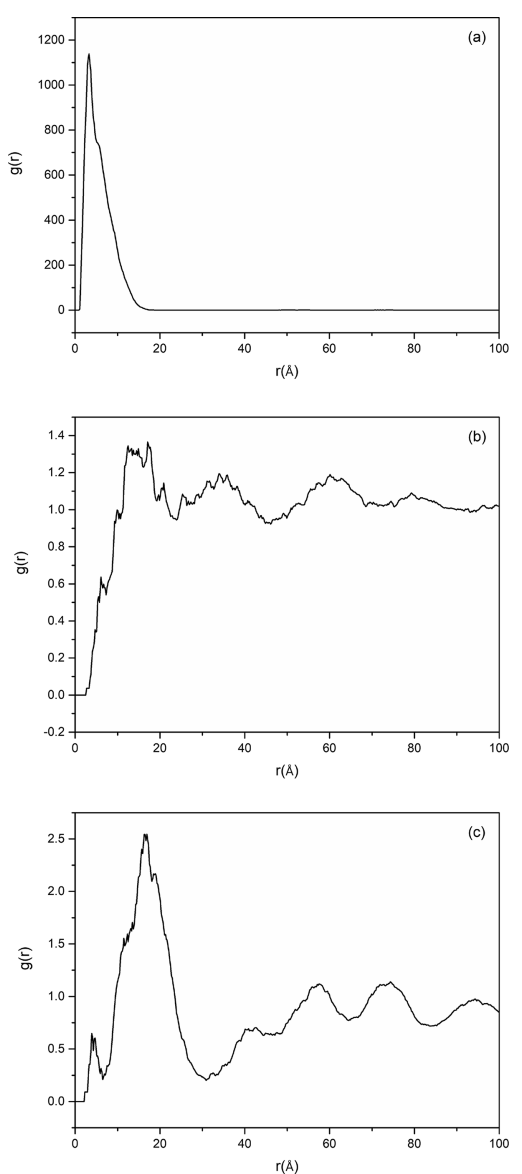

Figure 8. RDF of molecules in $n$-hexane $+\mathrm{CO}+$ water at $300 \mathrm{~K}$. (a) $\mathrm{H}_{2} \mathrm{O}-\mathrm{H}_{2} \mathrm{O}$ molecules, (b) $\mathrm{CO}-\mathrm{H}_{2} \mathrm{O}$ molecules, and (c) $n$-hexane$\mathrm{H}_{2} \mathrm{O}$ molecules.

molecules displays a distinct peak at $r$ of around $0.55 \mathrm{~nm}$, indicating that the hydrocarbon molecules are strongly aggregated. $n$-Hexane and $n$-octane present the lowest aggregation degree, while the aggregation of $n$-hexadecane and 1-methylnaphthalene is strongest, consistent with the London forces within these molecules. The aggregation behavior could prevent $\mathrm{CO}$
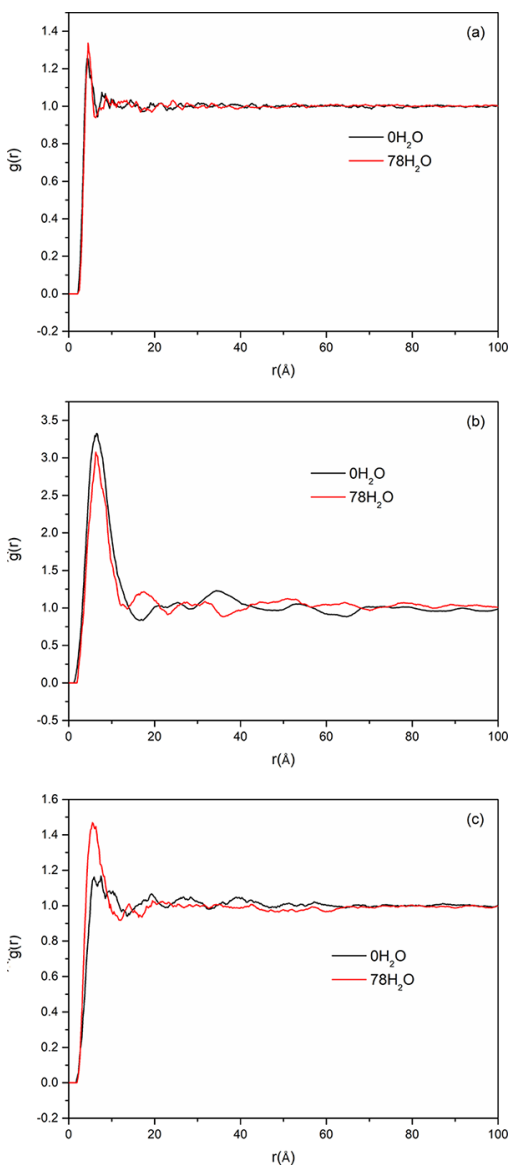

Figure 9. $\mathrm{RDF}$ of molecules in $n$-hexane $+\mathrm{CO}+$ water at $300 \mathrm{~K}$. (a) CO-CO molecules, (b) $n$-hexane $-n$-hexane molecules, and (c) CO$n$-hexane molecules.

molecules from interacting with hydrocarbon molecules. The RDF of $\mathrm{CO}-n$-hexadecane and $\mathrm{CO}-1$-methylnaphthalene molecules shows no peak, which further confirms that the interaction between $\mathrm{CO}$ and these two hydrocarbons is relatively weaker.

Figure 6 shows the $\mathrm{RDF}$ of $\mathrm{CO}-\mathrm{CO}$ molecules, hydrocarbon-hydrocarbon molecules, and $\mathrm{CO}$-hydrocarbon molecules at $300 \mathrm{~K}$ under different pressures for the $\mathrm{CO}+$ toluene system. The corresponding results for other $\mathrm{CO}+$ hydrocarbon systems are presented in Figures S3, S4, and S5 as supporting information. As can be seen, the $\mathrm{RDF}$ of $\mathrm{CO}-\mathrm{CO}$ molecules, toluene-toluene, and $\mathrm{CO}-$ toluene decreases with pressure increasing, among which the decrease of the RDF of toluenetoluene molecules is the most significant. It indicates that the aggregation of molecules is impeded by high pressure. When more $\mathrm{CO}$ molecules are pushed into the toluene molecules, the self-aggregates of toluene molecules are remarkably disintegrated, which can conversely facilitate the $\mathrm{CO}$ dissolution. The same tendency can be observed for $n$-octane, $n$-hexadecane, cyclohexane, and 1-methylnaphthalene. It appears that the selfaggregation of $n$-hexane molecules is little affected by altering the pressure. This could be attributed to its low self-aggregation degree and the limitation of pressure effect. On the whole, for $\mathrm{CO}+$ hydrocarbon systems, it is the $\mathrm{CO}$ molecules that disperse in the hydrocarbon molecular aggregates. The aggregation property of hydrocarbon molecules appears to be the key factor determining the $\mathrm{CO}$ solubility.

3.2. Role of Water in CO Dissolution in Model Hydrocarbons. Figure 7 shows the solubility of $\mathrm{CO}$ in different 

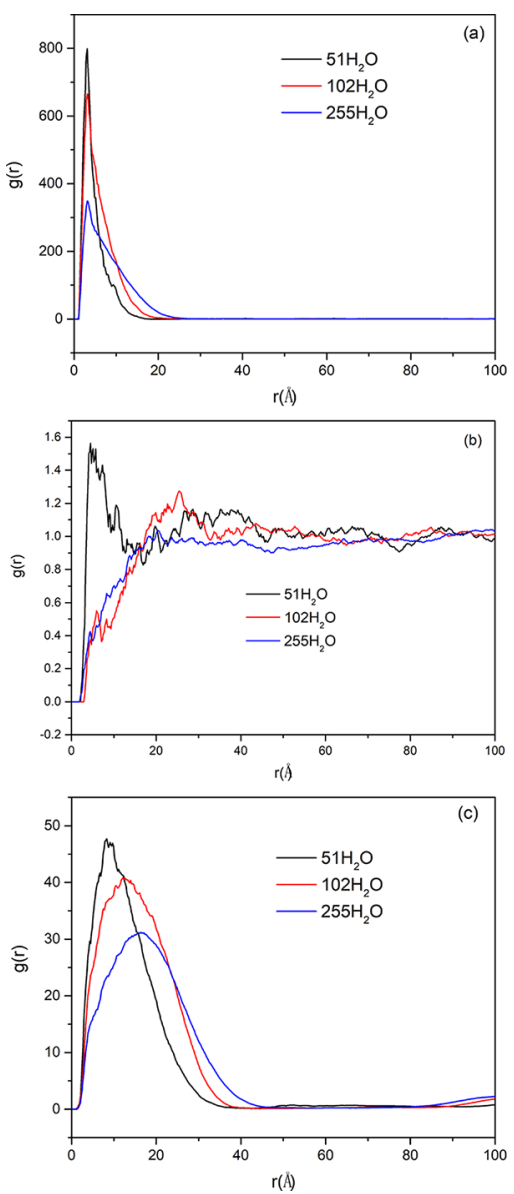

Figure 10. RDF of molecules in 1-methylnaphthalene $+\mathrm{CO}+$ water at $300 \mathrm{~K}$. (a) 1-methylnaphthalene $-\mathrm{H}_{2} \mathrm{O}$ molecules, (b) $\mathrm{CO}-\mathrm{H}_{2} \mathrm{O}$ molecules, and (c) $\mathrm{H}_{2} \mathrm{O}-\mathrm{H}_{2} \mathrm{O}$ molecules.

hydrocarbons at $323 \mathrm{~K}$ with different amounts of water. As can be seen, there is an apparent increase of $\mathrm{CO}$ solubility when water is added into the hydrocarbon. Since the solubility of $\mathrm{CO}$ in water is much lower, this result implies that there is synergism on $\mathrm{CO}$ dissolution between hydrocarbon and water. ${ }^{32}$ The synergism is not shown to be promoted with more water added, which might be restricted by the solubility of water in hydrocarbons. It can be inferred that the synergism could be mainly ascribed to the dissolved water in the hydrocarbons. The same observation has also been reported by Karandikar et al. ${ }^{33}$ The above results suggest that the water in the exploited oil benefits the dissolution of $\mathrm{CO}$ during thermal upgrading under $\mathrm{CO} /$ syngas and water.

The effect of water on the dispersion property of $\mathrm{CO}$ in $n$-hexane and 1 -methylnaphthalene is further studied by molecular dynamics simulation. The number of $\mathrm{H}_{2} \mathrm{O}$ molecules was determined to be 78 based on the 15 wt \% of the 107 $n$-hexane. Figure 8 displays the $\mathrm{RDF}$ of $\mathrm{H}_{2} \mathrm{O}-\mathrm{H}_{2} \mathrm{O}$ molecules, $\mathrm{CO}-\mathrm{H}_{2} \mathrm{O}$ molecules, and $n$-hexane $-\mathrm{H}_{2} \mathrm{O}$ molecules in the $\mathrm{CO}+n$-hexane + water system. The corresponding $\mathrm{RDF}$ of $\mathrm{CO}-\mathrm{CO}$ molecules, $n$-hexane $-n$-hexane molecules, and $\mathrm{CO}-$ $n$-hexane molecules is shown in Figure 9. As can be seen from the sharp peak of the RDF of $\mathrm{H}_{2} \mathrm{O}-\mathrm{H}_{2} \mathrm{O}$ molecules, $\mathrm{H}_{2} \mathrm{O}$ molecules are strongly aggregated with each other due to the high van der Waals forces (mainly dipole-dipole force) and hydrogen bonding forces. There is no obvious aggregation of $\mathrm{H}_{2} \mathrm{O}$ molecules with $\mathrm{CO}$ molecules, suggesting a low interaction between them.
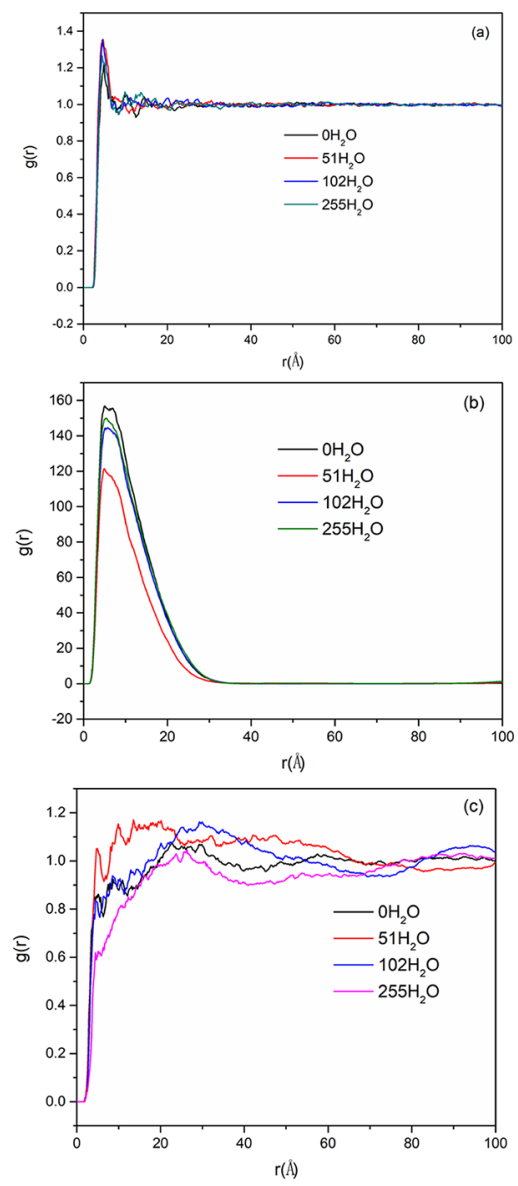

Figure 11. RDF of molecules in 1-methylnaphthalene + $\mathrm{CO}+$ water at $300 \mathrm{~K}$. (a) $\mathrm{CO}-\mathrm{CO}$ molecules, (b) 1-methylnaphthalene1-methylnaphthalene molecules, and (c) CO-1-methylnaphthalene molecules.

Thereby, the addition of $\mathrm{H}_{2} \mathrm{O}$ molecules has little effect on the weak aggregation of $\mathrm{CO}$ molecules. In contrast, a peak of $\mathrm{RDF}$ of $n$-hexane $-\mathrm{H}_{2} \mathrm{O}$ molecules around 2.5 is observed, which means that $\mathrm{H}_{2} \mathrm{O}$ molecules are aggregated with $n$-hexane molecules. It can be expected that the self-aggregation of $n$-hexane molecules is weakened by $\mathrm{H}_{2} \mathrm{O}$ molecules, which is well demonstrated by the decline of the peak of RDF of $n$-hexane $-n$-hexane molecules. As a consequence, the interaction of $\mathrm{CO}$ with $n$-hexane can be improved, as evidenced by the obvious increase of the peak value of RDF of $\mathrm{CO}-n$-hexane molecules. Correspondingly, the $\mathrm{CO}$ solubility is increased by the addition of water.

The variation of $\mathrm{CO}$ dispersion in 1-methylnaphthalene with different numbers of $\mathrm{H}_{2} \mathrm{O}$ molecules is also studied. The number of $\mathrm{H}_{2} \mathrm{O}$ molecules was determined to be 51,102 , and 255 based on the 10,20, and $50 \mathrm{wt} \%$ of the 651 -methylnaphthalene. Figure 10 shows the RDF of $\mathrm{H}_{2} \mathrm{O}-\mathrm{H}_{2} \mathrm{O}$ molecules, $\mathrm{CO}-\mathrm{H}_{2} \mathrm{O}$ molecules, and 1-methylnaphthalene- $\mathrm{H}_{2} \mathrm{O}$ molecules. The corresponding $\mathrm{RDF}$ of $\mathrm{CO}-\mathrm{CO}$ molecules, 1-methylnaphthalene-1-methylnaphthalene molecules, and CO-1-methylnaphthalene molecules is presented in Figure 11. The same trend can be found for the role of water on the dispersion of $\mathrm{CO}$ in 1-methylnaphthalene as that in $n$-hexane, which mainly lies in the breakage of 1-methylnaphthalene self-aggregates. When more $\mathrm{H}_{2} \mathrm{O}$ molecules exist, the peak of RDF of 1-methylnaphthalene$\mathrm{H}_{2} \mathrm{O}$ molecules is reduced significantly. The position of the peak is shifted to the higher part, indicating that the 1-methylnaphthalene $-\mathrm{H}_{2} \mathrm{O}$ aggregate becomes larger. This can be rationalized 
Table 3. Solubility of CO in Heavy Oil Distillates

\begin{tabular}{|c|c|c|c|c|c|c|}
\hline \multirow[b]{2}{*}{$T(\mathrm{~K})$} & \multicolumn{2}{|c|}{$\mathrm{FA}^{a}$} & \multicolumn{2}{|c|}{$\mathrm{FB}^{b}$} & \multicolumn{2}{|c|}{$\mathrm{FC}^{c}$} \\
\hline & $P(\mathrm{MPa})$ & $S(\mathrm{~mol} / \mathrm{kg})$ & $P(\mathrm{MPa})$ & $S(\mathrm{~mol} / \mathrm{kg})$ & $P(\mathrm{MPa})$ & $S(\mathrm{~mol} / \mathrm{kg})$ \\
\hline \multirow[t]{5}{*}{323} & 2.17 & $0.2286 \pm 0.0160$ & 2.04 & $0.1151 \pm 0.0030$ & 2.43 & $0.1089 \pm 0.0020$ \\
\hline & 4.25 & $0.4260 \pm 0.0036$ & 4.18 & $0.2368 \pm 0.0118$ & 4.23 & $0.1897 \pm 0.0064$ \\
\hline & 6.09 & $0.5646 \pm 0.0059$ & 5.93 & $0.3370 \pm 0.0210$ & 6.32 & $0.2838 \pm 0.0052$ \\
\hline & 8.15 & $0.7249 \pm 0.0035$ & 8.32 & $0.4764 \pm 0.0181$ & 8.16 & $0.3763 \pm 0.0095$ \\
\hline & 10.0 & $0.9138 \pm 0.0126$ & 9.80 & $0.5787 \pm 0.0248$ & 10.0 & $0.4711 \pm 0.0093$ \\
\hline \multirow[t]{5}{*}{373} & 2.04 & $0.2475 \pm 0.0158$ & 2.53 & $0.1537 \pm 0.0033$ & 2.16 & $0.1158 \pm 0.0047$ \\
\hline & 4.06 & $0.4869 \pm 0.0082$ & 4.14 & $0.2532 \pm 0.0120$ & 4.22 & $0.2432 \pm 0.0129$ \\
\hline & 6.02 & $0.7033 \pm 0.0164$ & 6.16 & $0.3839 \pm 0.0019$ & 5.77 & $0.3279 \pm 0.0004$ \\
\hline & 8.25 & $0.9755 \pm 0.0139$ & 8.25 & $0.5278 \pm 0.0002$ & 8.09 & $0.4584 \pm 0.0270$ \\
\hline & 9.76 & $1.125 \pm 0.0363$ & 10.1 & $0.6428 \pm 0.0255$ & 10.4 & $0.6110 \pm 0.0167$ \\
\hline \multirow[t]{5}{*}{423} & 2.43 & $0.3276 \pm 0.0042$ & 2.25 & $0.1493 \pm 0.0038$ & 2.27 & $0.1323 \pm 0.0013$ \\
\hline & 4.39 & $0.5824 \pm 0.0159$ & 4.20 & $0.2840 \pm 0.0015$ & 3.99 & $0.2464 \pm 0.0091$ \\
\hline & 6.23 & $0.8117 \pm 0.0193$ & 6.13 & $0.4275 \pm 0.0023$ & 5.91 & $0.3651 \pm 0.0034$ \\
\hline & 8.16 & $1.060 \pm 0.0455$ & 8.32 & $0.5773 \pm 0.0167$ & 8.02 & $0.4936 \pm 0.0126$ \\
\hline & 9.96 & $1.334 \pm 0.0311$ & 9.89 & $0.6965 \pm 0.0216$ & 9.89 & $0.6251 \pm 0.0042$ \\
\hline
\end{tabular}

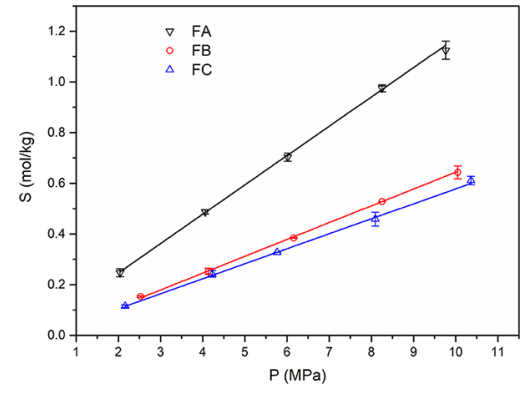

Figure 12. Solubility of CO in heavy oil distillates versus pressure at $373 \mathrm{~K}$.

by the larger aggregates of $\mathrm{H}_{2} \mathrm{O}-\mathrm{H}_{2} \mathrm{O}$ molecules. It can be predicted that the weakening effect of $\mathrm{H}_{2} \mathrm{O}$ molecules on 1-methylnaphthalene self-aggregation becomes lower gradually, as proved by the increase of RDF of 1-methylnaphthalene1-methylnaphthalene molecules with a greater number of $\mathrm{H}_{2} \mathrm{O}$ molecules added. The interaction of $\mathrm{CO}$ with $\mathrm{H}_{2} \mathrm{O}$ and 1-methylnaphthalene is still low. Overall, it is concluded that the promotion of $\mathrm{H}_{2} \mathrm{O}$ on $\mathrm{CO}$ dispersion in hydrocarbon mainly originates from the strong interaction of the $\mathrm{H}_{2} \mathrm{O}$ aggregate with the hydrocarbon molecule aggregate.

3.3. CO Dissolution in Heavy Oil Fractions. The solubility of $\mathrm{CO}$ in FA, FB, and FC from Canadian oil sand bitumen was measured at temperatures from 323 to $423 \mathrm{~K}$ and pressures up to $10 \mathrm{MPa}$. The data are listed in Table 3 . Consistent with the analysis result by model compounds, the solubility in these heavy oil fractions increases with pressure and temperature increasing. The variation of solubility as a function of pressure at $423 \mathrm{~K}$ is depicted in Figure 12 as an example. Under the same experimental conditions, the solubility of $\mathrm{CO}$ follows the order of FA $>$ FB $>$ FC. The solubility of CO in FA is extremely higher than the others. As seen from Table 2, FA presents the highest $\mathrm{H} / \mathrm{C}$ atomic ratio and lowest molecular weight. It indicates that FA is the least aromatic fraction. This is in good agreement with the hydrocarbon composition of these fractions as shown in Figure 13. The paraffin and naphthene contents in FA can be as high as 68 and 23 wt \%, respectively, while the portion of aromatics is only $6.7 \mathrm{wt} \%$. Since the paraffins and naphthenes facilitate the diffusion of $\mathrm{CO}$, their high

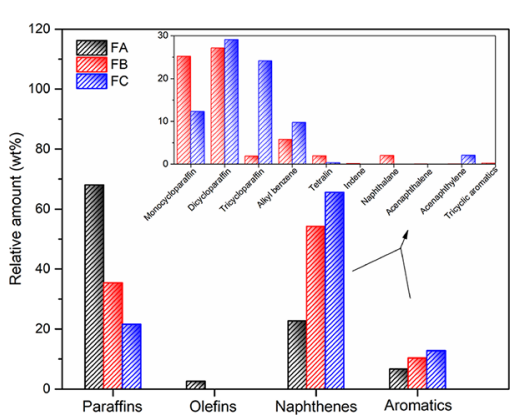

Figure 13. Hydrocarbon composition of FA, FB, and FC.

amount could significantly contribute to the high solubility of $\mathrm{CO}$ in FA. FB comprises more paraffins and naphthenes than FC, which could improve the CO dissolution. Meanwhile, the aromatic hydrocarbons in FC are of higher amount and more condensed than those in FB. This could hinder the $\mathrm{CO}$ dissolution in FC. During the partial upgrading process with $\mathrm{CO}$ and water, the increase of $\mathrm{CO}$ solubility can be expected as the hydrogenation of heavy oil proceeds.

The solubility of Canadian oil sand bitumen and that of its residues were simultaneously measured at temperatures ranging from 473 to $573 \mathrm{~K}$ and pressure up to $10 \mathrm{MPa}$, with results shown in Table 4. Figure 14 compares the solubility of $\mathrm{CO}$ in these feedstocks and FC as a function of pressure at $473 \mathrm{~K}$. Results indicate that the order of $\mathrm{CO}$ solubility is $\mathrm{FC}>\mathrm{HO}>\mathrm{AR}$ $>$ VR. This can be attributed to the decrease of the amount of saturates when the boiling range of heavy oil becomes higher. The ratio of saturates to aromatic fractions has decreased from 1.85 for FC to 0.54 for $\mathrm{HO}$ and even 0.24 for VR. The extensive aromatic structures mainly restrict the interaction between $\mathrm{CO}$ molecules and heavy residue molecules. Due to the presence of light distillates, heavy crude oil performs the highest solubility of CO. It can be inferred that recycling certain heavy oil fractions could improve the solubility of CO. Furthermore, these heavy oil fractions contain a portion of nitrogen, sulfur, and oxygen as shown in Table 2. The heteroatoms could contribute to the intermolecular forces of molecules by altering the polarizability and distortability and definitely affect the $\mathrm{CO}$ solubility. According to the present study, it seems that the solubility of $\mathrm{CO}$ in different 
Table 4. Solubility of CO in Heavy Oil and Its Residues

\begin{tabular}{|c|c|c|c|c|c|c|}
\hline \multirow[b]{2}{*}{$T(\mathrm{~K})$} & \multicolumn{2}{|c|}{$\mathrm{HO}^{a}$} & \multicolumn{2}{|c|}{$\mathrm{AR}^{b}$} & \multicolumn{2}{|c|}{$\mathrm{VR}^{c}$} \\
\hline & $P(\mathrm{MPa})$ & $S(\mathrm{~mol} / \mathrm{kg})$ & $P(\mathrm{MPa})$ & $S(\mathrm{~mol} / \mathrm{kg})$ & $P(\mathrm{MPa})$ & $S(\mathrm{~mol} / \mathrm{kg})$ \\
\hline \multirow[t]{5}{*}{473} & 2.05 & $0.1191 \pm 0.0141$ & 2.24 & $0.0858 \pm 0.0081$ & 1.93 & $0.0529 \pm 0.0121$ \\
\hline & 4.14 & $0.2401 \pm 0.0181$ & 4.28 & $0.1552 \pm 0.0121$ & 4.53 & $0.1135 \pm 0.0115$ \\
\hline & 6.18 & $0.3577 \pm 0.0231$ & 6.23 & $0.2239 \pm 0.0053$ & 6.31 & $0.1581 \pm 0.0224$ \\
\hline & 8.31 & $0.4758 \pm 0.0378$ & 8.25 & $0.2974 \pm 0.0060$ & 7.96 & $0.1977 \pm 0.0185$ \\
\hline & 9.98 & $0.5809 \pm 0.0313$ & 9.94 & $0.3573 \pm 0.0120$ & 10.2 & $0.2519 \pm 0.0256$ \\
\hline \multirow[t]{5}{*}{523} & 2.21 & $0.1586 \pm 0.0095$ & 2.27 & $0.0964 \pm 0.0032$ & 2.15 & $0.0813 \pm 0.0087$ \\
\hline & 4.16 & $0.3021 \pm 0.0193$ & 4.31 & $0.1804 \pm 0.0077$ & 4.20 & $0.1425 \pm 0.0126$ \\
\hline & 5.94 & $0.4423 \pm 0.0198$ & 6.35 & $0.2681 \pm 0.0135$ & 6.04 & $0.2087 \pm 0.0157$ \\
\hline & 8.12 & $0.6048 \pm 0.0222$ & 8.17 & $0.3387 \pm 0.0207$ & 8.05 & $0.2808 \pm 0.0272$ \\
\hline & 10.1 & $0.7573 \pm 0.0384$ & 10.1 & $0.4133 \pm 0.0215$ & 10.1 & $0.3492 \pm 0.0302$ \\
\hline \multirow[t]{5}{*}{$573 \mathrm{~K}$} & 2.01 & $0.1671 \pm 0.0130$ & 2.22 & $0.1286 \pm 0.0054$ & 2.21 & $0.0971 \pm 0.0102$ \\
\hline & 3.98 & $0.3307 \pm 0.0154$ & 4.32 & $0.2565 \pm 0.0074$ & 4.02 & $0.1693 \pm 0.0147$ \\
\hline & 6.04 & $0.5012 \pm 0.0201$ & 6.20 & $0.3723 \pm 0.0208$ & 5.94 & $0.2465 \pm 0.0230$ \\
\hline & 8.02 & $0.6542 \pm 0.0185$ & 8.15 & $0.4961 \pm 0.0268$ & 8.10 & $0.3181 \pm 0.0196$ \\
\hline & 10.0 & $0.8334 \pm 0.0237$ & 10.0 & $0.6088 \pm 0.0170$ & 10.4 & $0.4008 \pm 0.0225$ \\
\hline
\end{tabular}

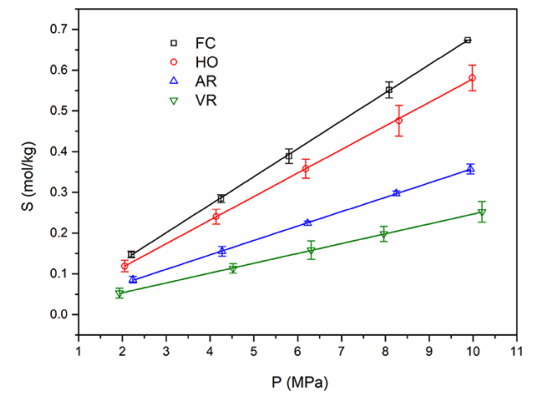

Figure 14. Solubility of $\mathrm{CO}$ in heavy crude oil and its residues versus pressure at $473 \mathrm{~K}$.

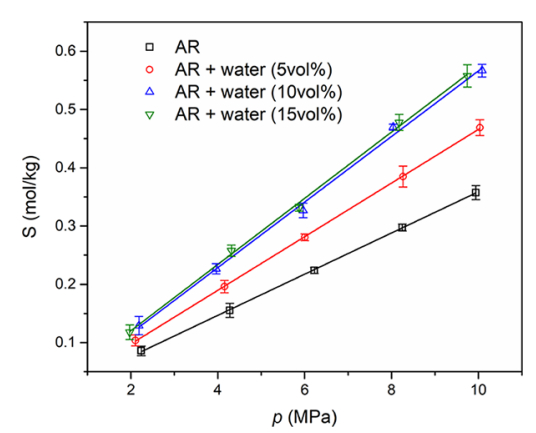

Figure 15. Solubility of $\mathrm{CO}$ in atmospheric residues with different amounts of water versus pressure at $473 \mathrm{~K}$.

heavy oil fractions can be simply compared by analyzing the group or hydrocarbon-class composition. In addition, the partial upgrading of heavy oil with $\mathrm{CO}$ and water involved the solid catalyst phase. As studied by Cai et al., ${ }^{34}$ the different solid additives including hydrotreating catalysts could raise the apparent solubility of hydrogen in petroleum fractions. Therefore, the impact of solid additives is worth studying in future works to enhance the $\mathrm{CO}$ dispersion and dissolution. Figure 15 shows the effect of water on the solubility of CO in AR at $473 \mathrm{~K}$. It can be clearly seen that water could promote the $\mathrm{CO}$ dissolution in AR. The extent of promotion might be limited by the solubility of water in $\mathrm{AR}$, indicating that the soluble water in $\mathrm{AR}$ is the promoter for $\mathrm{CO}$ dissolution.

\section{CONCLUSIONS}

The structure-solubility relationship of $\mathrm{CO}$ dispersion in organic liquids was explored. The dispersion behavior of $\mathrm{CO}$ in different molecules was simulated by the molecular dynamics calculation. The role of water on CO dispersion in these systems was also studied. Experimental data show that the increase of both paraffinic chain length and aromaticity of molecules could hinder the dissolution of CO. By theoretical calculation, it is found that $n$-hexadecane and 1-methylnaphthalene present the strongest self-aggregation tendency, resulting in the low interaction with $\mathrm{CO}$. The intermolecular forces of hydrocarbons appear to be the key factor determining the $\mathrm{CO}$ solubility. The dissolved $\mathrm{H}_{2} \mathrm{O}$ molecules could weaken the intermolecular forces of hydrocarbons and thus increase the $\mathrm{CO}$ solubility. Based on the model system study, the solubility of $\mathrm{CO}$ in complex petroleum distillates and heavy residues is rationalized by their molecular composition, which is mainly dependent on the relative proportion of paraffins to aromatics.

\section{ASSOCIATED CONTENT}

Supporting Information

The Supporting Information is available free of charge at https://pubs.acs.org/doi/10.1021/acsomega.1c03060.

The CO solubility in ethanol (Figure S1); the variation of energies and temperatures during 100 ps NVT and 300 ps NPT simulation for the $2000 \mathrm{CO}+107 n$-hexane system. (Figure S2); the RDF of CO-CO molecules for different hydrocarbon + $\mathrm{CO}$ systems at $300 \mathrm{~K}$ under different pressures (Figure S3); the RDF of hydrocarbonhydrocarbon molecules for different hydrocarbon $+\mathrm{CO}$ systems at $300 \mathrm{~K}$ under different pressures (Figure S4); and the $\mathrm{RDF}$ of $\mathrm{CO}$-hydrocarbon molecules for different hydrocarbon $+\mathrm{CO}$ systems at $300 \mathrm{~K}$ under different pressures (Figure S5) (PDF)

\section{AUTHOR INFORMATION}

\section{Corresponding Author}

He Liu - State Key Laboratory of Heavy Oil Processing, College of Chemical Engineering, China University of Petroleum (East China), Qingdao, Shandong 266580, China; 이이.org/ 0000-0002-1450-5451; Email: liuhe@upc.edu.cn 


\section{Authors}

Shiguang Fan - State Key Laboratory of Heavy Oil Processing, College of Chemical Engineering, China University of Petroleum (East China), Qingdao, Shandong 266580, China; (1) orcid.org/0000-0002-0917-6681

Jian Wang - State Key Laboratory of Heavy Oil Processing, College of Chemical Engineering, China University of Petroleum (East China), Qingdao, Shandong 266580, China; (1) orcid.org/0000-0003-3706-4481

Hao Liu - State Key Laboratory of Heavy Oil Processing, College of Chemical Engineering, China University of Petroleum (East China), Qingdao, Shandong 266580, China

Aijun Guo - State Key Laboratory of Heavy Oil Processing, College of Chemical Engineering, China University of Petroleum (East China), Qingdao, Shandong 266580, China

Kun Chen - State Key Laboratory of Heavy Oil Processing, College of Chemical Engineering, China University of Petroleum (East China), Qingdao, Shandong 266580, China; ○ orcid.org/0000-0002-8556-8900

Zongxian Wang - State Key Laboratory of Heavy Oil Processing, College of Chemical Engineering, China University of Petroleum (East China), Qingdao, Shandong 266580, China

Litao Wang - Petrochina Petrochemical Research Institute, Beijing 102249, China

Complete contact information is available at:

https://pubs.acs.org/10.1021/acsomega.1c03060

\section{Notes}

The authors declare no competing financial interest.

\section{ACKNOWLEDGMENTS}

This work was supported by the National Natural Science Foundation of China (21908248), the Fundamental Research Funds for the Central Universities (19CX02013A and 20CX02206A), the China National Petroleum Corporation (PRIKY19022), and the Development Fund of State Key Laboratory of Heavy Oil Processing.

\section{REFERENCES}

(1) Alemán-Vázquez, L. O.; Torres-Mancerac, P.; Ancheyta, J.; Ramírez-Salgado, J. Use of hydrogen donors for partial upgrading of heavy petroleum. Energy Fuels 2016, 30, 9050-9060.

(2) Gray, M. R. Fundamentals of partial upgrading of bitumen. Energy Fuels 2019, 33, 6843-6856.

(3) Shu, G.; Bu, K.; Zhao, B.; Zheng, S. Separation of SAGD produced emulsions through a combined pre-dewatering and demulsification process. J. Pet. Sci. Eng. 2021, 201, 108493-108505.

(4) Ng, F. T. T. Upgrading heavy oil/bitumen emulsions via in situ hydrogen generation. Prepr. Symp. - Am. Chem. Soc., Div. Fuel Chem. 1998, 43, 456-460.

(5) Ng, F. T. T.; Milad, I. K. Catalytic desulphurization of benzothiophene in an emulsion via in situ generated $\mathrm{H}_{2}$. Appl. Catal., A 2000, 200, 243-254.

(6) Jia, L. Oil sands bitumen emulsion upgrading by using in situ hydrogen generated through the water gas shift reaction. Waterloo: University of Waterloo, 2014

(7) Arai, K.; Adschiri, T.; Watanabe, M. Hydrogenation of hydrocarbons through partial oxidation in supercritical water. Ind. Eng. Chem. Res. 2000, 39, 4697-4701.

(8) Qureshi, M. S.; Le Nedelec, T.; Guerrero-Amaya, H.; Uusi-Kyyny, P.; Richon, D.; Alopaeus, V. Solubility of carbon monoxide in bio-oil compounds. J. Chem. Thermodyn. 2016, 105, 296-311.
(9) Srinivas, S.; Field, R. P.; Watanasiri, S.; Herzog, H.J. Correlation to predict solubility of hydrogen and carbon monoxide in heavy paraffins. Fluid Phase Equilib. 2012, 320, 11-25.

(10) Srivatsan, S.; Yi, X.; Robinson, R. L., Jr.; Gasem, K. A. M. Solubilities of carbon monoxide in heavy normal paraffins at temperatures from 311 to $423 \mathrm{~K}$ and pressures to $10.2 \mathrm{MPa}$. J. Chem. Eng. Data 1995, 40, 237-240.

(11) Gao, W.; Robinson, R. L.; Gasem, K. A. M. High-pressure solubilities of hydrogen, nitrogen, and carbon monoxide in dodecane from 344 to $410 \mathrm{~K}$ at pressures to 13.2 MPa. J. Chem. Eng. Data 1999, 44, 130-132.

(12) Park, J.; Yi, X.; Gasem, K. A. M.; Robinson, R. L., Jr. Solubilities of carbon monoxide in aromatic hydrocarbons at temperatures from 323 to $433 \mathrm{~K}$ and pressures to $23.3 \mathrm{MPa}$. J. Chem. Eng. Data 1995, 40, 245247.

(13) Jáuregui-Haza, U. J.; Pardillo-Fontdevila, E. J.; Wilhelm, A. M.; Delmas, H. Solubility of hydrogen and carbon monoxide in water and some organic solvents. Lat. Am. Appl. Res. 2004, 34, 71-74.

(14) Gao, W.; Robinson, R. L.; Gasem, K. A. M. Solubilities of hydrogen in hexane and of carbon monoxide in cyclohexane at temperatures from 344.3 to $410.9 \mathrm{~K}$ and pressures to $15 \mathrm{MPa}$. J. Chem. Eng. Data 2001, 46, 609-612.

(15) Abedi, S. J.; Seyfaie, S.; Shaw, J. M. Unusual retrograde condensation and asphaltene precipitation in a model heavy oil system. Pet. Sci. Technol. 1998, 16, 209-226.

(16) Cai, H. Y.; Shaw, J. M.; Chung, K. H. Hydrogen solubility measurements in heavy oil and bitumen cuts. Fuel 2001, 80, 10551063.

(17) Baird, Z. S.; Uusi-Kyyny, P.; Oja, V.; Alopaeus, V. Hydrogen solubility of shale oil containing polar phenolic compounds. Ind. Eng. Chem. Res. 2017, 56, 8738-8747.

(18) Nasery, S.; Barati-Harooni, A.; Tatar, A.; Najafi-Marghmaleki, A.; Mohammadi, A. H. Accurate prediction of solubility of hydrogen in heavy oil fractions. J. Mol. Liq. 2016, 222, 933-943.

(19) Saajanlehto, M.; Uusi-Kyyny, P.; Alopaeus, V. Hydrogen solubility in heavy oil systems: Experiments and modeling. Fuel 2014, 137, 393-404.

(20) Ji, S.; Wang, Z.; Guo, A.; Zhou, Y.; Chen, K. Determination of hydrogen solubility in heavy fractions of crude oils by a modified direct method. J. Chem. Eng. Data 2013, 58, 3453-3457.

(21) Tonner, S. P.; Wainwright, M. S.; Trimm, D. L.; Cant, N. W. Solubility of carbon monoxide in alcohols. J. Chem. Eng. Data 1983, 28, $59-61$.

(22) Uusi-Kyyny, P.; Pakkanen, M.; Linnekoski, J.; Alopaeus, V. Hydrogen solubility measurements of analyzed tall oil fractions and a solubility model. J. Chem. Thermodyn. 2017, 105, 15-20.

(23) Anderson, L. R.; Yang, Q.; Ediger, A. M. Comparing gas transport in three polymers via molecular dynamics simulation. Phys. Chem. Chem. Phys. 2018, 20, 22123-22133.

(24) Yuan, H.; Gosling, C.; Kokayeff, P.; Murad, S. Prediction of hydrogen solubility in heavy hydrocarbons over a range of temperatures and pressures using molecular dynamics simulations. Fluid Phase Equilib. 2010, 299, 94-101.

(25) Economou, I. G.; Garrido, N. M.; Makrodimitri, Z. A. Prediction of microscopic structure and physical properties of complex fluid mixtures based on molecular simulation. Fluid Phase Equilib. 2010, 296, 125-132.

(26) Li, C.; Pu, H.; Zhong, X.; Li, Y.; Zhao, J. X. Interfacial interactions between Bakken crude oil and injected gases at reservoir temperature: $\mathrm{A}$ molecular dynamics simulation study. Fuel 2020, 276, 118058118064 .

(27) Guo, A.; Wang, Z.; Zhang, H.; Zhang, X.; Wang, Z. Hydrogen transfer and coking propensity of petroleum residues under thermal processing. Energy Fuels 2010, 24, 3093-3100.

(28) Yang, Z.; Li, M.; Peng, B.; Lin, M.; Dong, Z. Dispersion property of $\mathrm{CO}_{2}$ in oil. 1. Volume expansion of $\mathrm{CO}_{2}+$ alkane at near critical and supercritical condition of $\mathrm{CO}_{2}$. J. Chem. Eng. Data 2012, 57, 882-889.

(29) Yang, Z.; Li, M.; Peng, B.; Lin, M.; Dong, Z. Dispersion property of $\mathrm{CO}_{2}$ in oil. 2: Volume expansion of $\mathrm{CO}_{2}+$ organic liquid at near- 
critical and supercritical conditions of $\mathrm{CO}_{2}$. J. Chem. Eng. Data 2012, 57, 1305-1311.

(30) Yang, Z.; Li, M.; Peng, B.; Lin, M.; Dong, Z. Dispersion property of $\mathrm{CO}_{2}$ in oil. Part 3: Aggregation of $\mathrm{CO}_{2}$ molecule in organic liquid at near critical and supercritical condition of $\mathrm{CO}_{2}$. J. Dispersion Sci. Technol. 2014, 35, 143-149.

(31) Yang, Z.; Li, M.; Peng, B.; Lin, M.; Dong, Z. Volume expansion of $\mathrm{CO}_{2}+$ oil at near critical and supercritical conditions of $\mathrm{CO}_{2}$. Fuel 2013, $112,283-288$.

(32) Takahashi, M.; Kobayashi, Y.; Takeuchi, H. Diffusion coefficients and solubilities of carbon dioxide in binary mixed solvents. J. Chem. Eng. Data 1982, 27, 328-331.

(33) Karandikar, B. M.; Morsi, B. I.; Shah, Y. T.; Carr, N. L. Effect of water on the solubility and mass transfer coefficients of $\mathrm{CO}$ and $\mathrm{H}_{2}$ in a Fischer-Tropsch liquid. Chem. Eng. J. 1986, 33, 157-168.

(34) Cai, H. Y.; Shaw, J. M.; Chung, K. H. The impact of solid additives on the apparent solubility of hydrogen in petroleum fractions and model hydrocarbon liquids. Fuel 2001, 80, 1065-1077. 
